\title{
First-year medical undergraduate students opinion about the use of radiology in gross anatomy course
}

\author{
SILVA, V. A. ${ }^{1,2 *}$, VILELA, D. M. ${ }^{1}$, GONÇALVES, F. R. ${ }^{1}$ and REGACINI, R. ${ }^{1}$ \\ ${ }^{1}$ School of Medicine, Universidade Anhembi Morumbi, Rua Dr. Almeida Lima, 1134, \\ CEP 03164-000, São Paulo, SP, Brazil \\ ${ }^{2}$ Faculty of Medical Sciences, Santa Casa de São Paulo, Rua Dr. Cesário Motta Jr., 61, \\ CEP 01221-020, São Paulo, SP, Brazil \\ *E-mail: vivianasilva@anhembimorumbi.edu.br
}

\begin{abstract}
Introduction: Although the importance of anatomy teaching in the undergraduate medical curriculum is incontestable, the lack of knowledge retention and clinical application are the greatest challenges for anatomy teachers. New teaching methodologies are replacing cadaver' dissection in many schools around the world and the usage of radiologic images can become a valuable resource for student's learning the human body structures. The aim of this article was to analyze the perception of first-year undergraduate medical students in the usage of radiology in gross human anatomy course. Materials and methods: One hundred students answered a 30 questions survey using a 5-point Likert scale about the usage of radiologic images in the human anatomy classes. Results: Most subjects have shown desire and the availability to learn human anatomy using images. After the usage of radiologic images there has been an increase on the subjective aspects of the human body such as admiration and respect, an improvement in the correlation of human anatomy with clinical aspects and in the three dimensional perception of the human body anatomic structures. Conclusions: Most of the research participants evaluated the usage of radiologic images as positive and beneficial for the teaching and learning human anatomy as it increases the interest for anatomy and it can favor learning and clinical practice performance. Results shows that according to students' opinion the usage of radiology can be an excellent complement in human anatomy learning and can induce us to think it can prepare and train more competent doctors in diagnostic imaging.
\end{abstract}

Keywords: anatomy, radiology, images, medical education, survey.

\section{Introduction}

Ensure that important issues are adequately strengthened over the years of training is a challenge in the curriculum of medical schools around the world. In traditional curriculum, anatomy is taught during the early years and, since this knowledge is obtained separated of clinical training, it creates difficulty for students to retain it and to understand its application in a clinical context (WRIGHT, 2012; ZUMWALT, LUFLER, MONTEIRO et al., 2010).

Modern computing resources provide unique opportunities for learning and have served as a platform for most of this reform. Electronic presentations of magnetic resonance (MRIs), $\mathrm{X}$-rays, computed tomography (CT) scans and ultrasounds have quickly become a bridge to a more close context with the clinic for teaching anatomy to medical students in the first year (MARKER, BANSAL, JULURU et al., 2010).

In this context radiology offers valuable resources for learning the structure and function of the human body as it allows visualization in vivo compared with the normal and altered anatomy of cadaver and the exposure of students to a variety of diseases (GUNDERMAN and WILSON, 2005).

Renewing interest in diagnostic imaging in medical education provides valuable learning opportunities for students to learn the anatomical relationships among organs and structures, significantly improves the skills of identifying anatomical structures and allows the visualization of the anatomical variations that are inherent to the human body (MILES,
2005; LUFLER, ZUMWALT, ROMNEY et al., 2010; MIRSADRAEE, MANKAD, MCCOUBRIE et al., 2012; BROWN, ADHIKARI, MARX et al., 2012).

Brown, Adhikari, Marx et al. (2012) studied first-year undergraduate medicine students' opinion to the use of ultrasound images in the gross anatomy classes. In Brown's study most students agreed that ultrasound-based teaching increased students' knowledge of anatomy and increases confidence to perform invasive procedures in the future. The usage of radiology in human anatomy teaching establishes a symbiotic relationship and has a great potential.

However few studies describe the students and professors' opinions about the usage of radiology as an anatomy teaching tool. The aim of this study is to analyze the perception of first-year undergraduate medical students in using radiology in a gross human anatomy course.

\section{Materials and Methods}

\subsection{Subjects and anatomy practical classes}

A cross-sectional study was conducted with 110 first-year's medical undergraduate students from the Universidade Anhembi Morumbi (Sao Paulo, Brazil) in the period of June through November 2012. In the pre-clinical curriculum the students take 60 hours gross anatomy course delivered by using multiple teaching tools like: radiology, surface anatomy, body painting, 
body projection, anatomical resin models, surgical videos, anatomical software, textbooks and no cadavers.

Radiology is an important part of our gross anatomy course. During the classes X-ray images were used for the visualization of bones, airway and digestive tract; MRI for visualization of joints, muscles, brain and heart; ultrasound to visualize muscles (Figure 1), urinary and genital tract and CT for the visualization of thoracic, abdominal and pelvic viscera.

After the course, volunteers responded to a survey questionnaire to evaluate their perception of human anatomy teaching using radiology. The instrument for data collection was undertaken using a 5 -point Likert scale. The questions were proposed by the researchers of this study or based on similar studies (REES, BRADLEY, COLLETT et al., 2005; AGGARWAL, BROUGH and ELLIS, 2006; MCMENAMIN, 2008; COLLETT, KIRVELL, NAKORN et al., 2009; FINN and MCLACHLAN, 2010).

Questions were randomized and presented in a single questionnaire (Table 1). The main objective of this questionnaire was to analyze what was the first-year undergraduate medical students consensus about the use of radiology during the gross anatomy course.

All participation was voluntary and the instrument for data collection was anonymous. All first year medical students from 2012 intake were asked to fill in the questionnaire at the end of their last anatomy session and all of them have signed a term of free and informed consent. They were asked to rate each question from 2 (completely agree) to -2 (completely disagree).

\subsection{Data analysis}

The analysis of all quantitative variables was conducted through the observation of the minimum and maximum value ranges, average values, standard deviations and medians. To qualitative variables absolute and relative frequencies were calculated to test the homogeneity between proportions and it was used the chi-squared test or Fisher's exact test. Spearman's correlation coefficient was calculated to evaluate the association between the statements. The reliability was analyzed using Chronbach's alpha. Significance level of $\mathrm{p}<0.05$ was used.

\section{Results}

\subsection{Demographics}

From the cohort of 110 student volunteers there were a total of 100 questionnaire respondents, a response rate of $91 \%$. The participants who answered the questionnaire had between 17 and 35 years old (average of 21.02 years old with standard deviation of 3,31 and median of 20 years old). Sixty-three $(63.0 \%)$ were females and thirty-seven $(37.0 \%)$ males.

\subsection{Reliability}

The reliability was analyzed using Chronbach's coefficient alpha. The reliability for the 30 Likert scale statements was 0.885 .

\subsection{Participants' opinions}

Statistical analysis showed no difference opinion comparing gender and different ages.

Most participants $(67 \%)$ agree that anatomy classes with radiology is fun, giving a stimulating and challenging aspect for learning gross anatomy $(73 \%)$ but only half of the participants (47\%) considered that the classmates showed real commitment with the class. Seventy-three percent $(73 \%)$ of the participants agreed that they had more will to study the human body after the classes with radiology and the usage of this resource has improved learning (96\%) and made students feel active in the search of knowledge (69\%). Just 14\% of the participants think that radiology classes during the gross anatomy course should not be repeated and $18 \%$ would not like to have more radiology classes, but most of the students (84\%) approved them (Table 1).

Only $14 \%$ of participants reported feeling troubled by observing the human body in the diagnostic images and $60 \%$ reported that started appreciating and admiring more the human organism after the classes (Table 1).

Over $70 \%$ of participants agreed that the usage of radiology stimulates the study of anatomy clinical applications, makes them feel more prepared to interact with their patients in the future $(78 \%)$ and $93 \%$ realized that they are studying in the human anatomy class significant content to the medical clinical practice (Table 1).
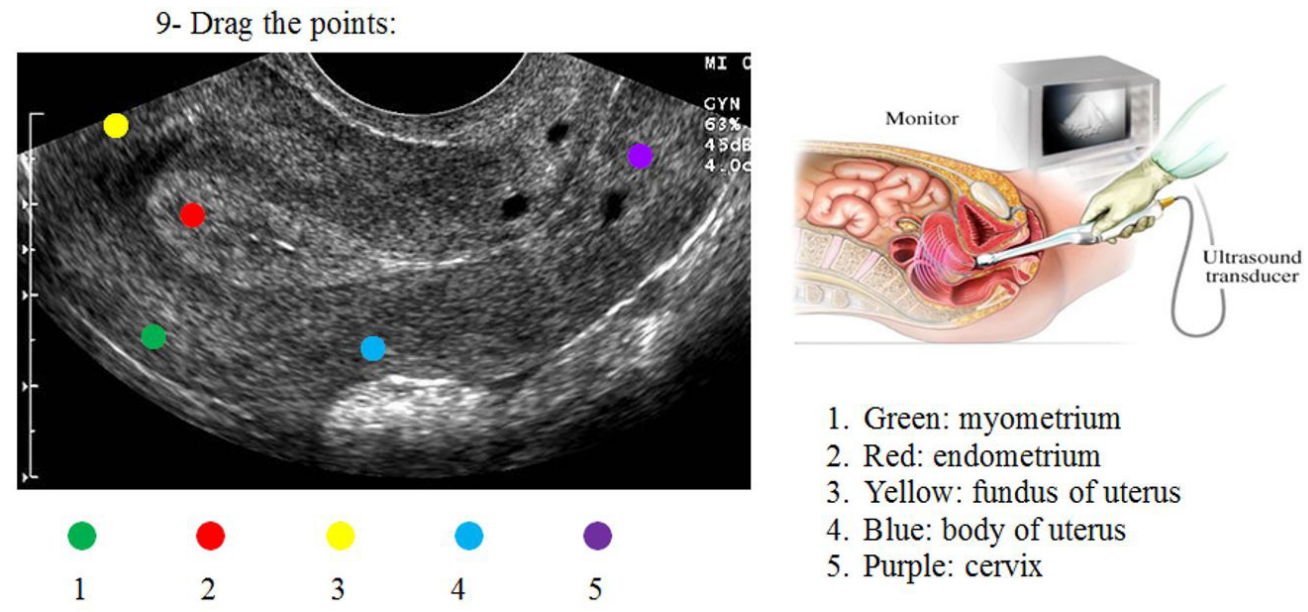

1. Green: myometrium

2. Red: endometrium

3. Yellow: fundus of uterus

4. Blue: body of uterus

5. Purple: cervix

Figure 1. Similar to this ultrasound image, various computed tomographic, magnetic resonance imaging and radiographic images were selected to demonstrate normal anatomy. 
Almost all participants (98\%) considered that learning the position of human body structures is important to the clinic and $90 \%$ believe that the teaching of radiology allows to correlate the theoretical classes with the clinical practice (Table 1).

Most participants $(71 \%)$ were able to realize three dimensionality of the studied organs, comprehending better where the structures are located in the organism $(90 \%)$ and its relation with organs and adjacent structures (87\%). After the radiology class most of the students (71\%) feel capable of identifying structures and able to making the diagnostic imaging in the future (69\%). The participants still believe that this tool portrays in details the human body $(75 \%)$. Eighty-seven percent thinks that radiology is a useful tool to learning human anatomy, awakens the students' interest for anatomy $(77 \%)$ and makes them more willing to comprehend it $(74 \%)$ (Table 1$)$.

Table 1. First-year medical students opinion about radiology use in gross anatomy.

\begin{tabular}{|c|c|c|c|}
\hline & $\alpha$ & Statement & LA \% \\
\hline 1 & 0.878 & The class with radiology is fun. & 67 \\
\hline 2 & 0.878 & The learning environment with radiology is stimulating and challenging. & 73 \\
\hline 3 & 0.885 & Classmates showed commitment with the class and will to learn. & 47 \\
\hline 4 & 0.880 & I had more will to learn and study after the radiology classes. & 73 \\
\hline 5 & 0.880 & The usage of radiology during the class period improved my learning. & 96 \\
\hline 6 & 0.895 & I think the radiology class should not be repeated. & 14 \\
\hline 7 & 0.878 & I felt actively looking for knowledge during the classes. & 69 \\
\hline 8 & 0.878 & I would not like to have more classes with radiology. & 18 \\
\hline 9 & 0.882 & I would like to have more classes with radiology. & 84 \\
\hline 10 & 0.895 & I was bothered to observe the human body in the radiological images. & 14 \\
\hline 11 & 0.878 & I started appreciating (admiring) more the human body after radiology classes. & 60 \\
\hline 12 & 0.875 & $\begin{array}{l}\text { The radiology classes stimulated me to study more about the human anatomy clinical } \\
\text { application. }\end{array}$ & 74 \\
\hline 13 & 0.880 & After participating in the radiology classes I feel more prepared to talk to my patients. & 78 \\
\hline 14 & 0.881 & $\begin{array}{l}\text { The radiology classes gave me consciousness that I am learning human anatomy content that I } \\
\text { need in my clinical practice. }\end{array}$ & 93 \\
\hline 15 & 0.885 & $\begin{array}{l}\text { Learning the human body anatomical structures positions is important to the professional } \\
\text { practice. }\end{array}$ & 98 \\
\hline 16 & 0.878 & $\begin{array}{l}\text { Teaching anatomy through radiology allows students to correlate learnt aspects during } \\
\text { theoretic classes with the clinical practice. }\end{array}$ & 90 \\
\hline 17 & 0.879 & The classes with radiology made me see organs three dimensionally. & 71 \\
\hline 18 & 0.880 & $\begin{array}{l}\text { After radiology classes I started better comprehending where in the human body are located } \\
\text { the structures previously studied in the laboratories. }\end{array}$ & 90 \\
\hline 19 & 0.878 & $\begin{array}{l}\text { Through the radiology classes you can comprehend organs and systems locations' as well as its } \\
\text { relations and adjacent structures. }\end{array}$ & 87 \\
\hline 20 & 0.879 & After radiology classes I feel capable to recognize and point out taught structures. & 71 \\
\hline 21 & 0.881 & $\begin{array}{l}\text { After radiology classes with normal diagnostic images I feel more prepared to see radiological } \\
\text { alterations (abnormalities and variations). }\end{array}$ & 69 \\
\hline 22 & 0.888 & The radiology class depicts the human body in details. & 75 \\
\hline 23 & 0.881 & Radiology is a useful tool to learn human anatomy. & 87 \\
\hline 24 & 0.877 & The usage of radiology during class awakens students' interest about anatomy. & 77 \\
\hline 25 & 0.878 & After radiology classes I felt more will to comprehend the human body structure. & 74 \\
\hline 26 & 0.877 & The radiology classes helped me to retain (memorize) what I learned in the laboratory. & 84 \\
\hline 27 & 0.879 & I was able to see in radiology classes the anatomical structured indicated by the professors. & 80 \\
\hline 28 & 0.881 & $\begin{array}{l}\text { During the radiology classes the professor correlated the diagnostic images to the anatomical } \\
\text { resin models available in the laboratory and the emphasized theoretical content }\end{array}$ & 82 \\
\hline 29 & 0.892 & The radiology class is an unnecessary resource to study anatomy. & 11 \\
\hline 30 & 0.890 & $\begin{array}{l}\text { I think that only the use of books and resin anatomical models are enough to dominate the } \\
\text { human anatomy knowledge. }\end{array}$ & 11 \\
\hline
\end{tabular}

LA: level of agreement; $\alpha$ : Chronbach's coefficient alpha. 
Eighty-four percent ( $84 \%$ ) of participants consider that the radiology anatomy class helped in the knowledge retention and were able to see in the images the anatomical structures indicated by the professor $(80 \%)$, being that $82 \%$ of the participants indicated that the professor during the radiology classes correlated the diagnostic images to the anatomical resin models available in the laboratory and emphasized the theoretical content. Eleven percent of participants believe that the usage of radiology is unnecessary to the anatomy study and that only the use of books and anatomic resin models would be enough for learning (Table 1).

\subsection{Correlation between statements}

Considering the 30 affirmations that have decreased the sample's reliability, it's highlighted that 14 of the following questions decrease the Alpha to -0.880 . The questions are: $1,2,7,8,11,12,16,17,19,20,24,25,26,27$ (Table 1). These questions are more stable or have a higher importance in the instrument and for this reason only these were taken into consideration to analyze Spearman's correlation coefficient. Correlation analysis for the instrument revealed a significant positive correlation between all statements groups.

It's been observed a positive correlation (high scores of a proposition if associated with high scores of other proposition) between almost all studied statements (Table 2). Questions that presented high scores associate between themselves to all of the selected statements.

No correlation exists between two variable pairs. Statement 11 ("I started appreciating (admiring) more the human body after radiology classes.") does not correlate with questions 8 ("I would not like to have more classes with radiology.) and
16 ("Teaching anatomy through radiology allows students to correlate learnt aspects during theoretic classes with the clinical practice.), possibly implying that appreciating the human body is not important for the student to will to have more anatomy classes with radiology or correlate the learnt aspects during theoretical classes with the payhologies seen in the clinic.

\section{Discussion}

Most of the participants had a positive attitude towards radiology use in the anatomy classes. Students considered this resource fun, stimulating, challenging and would like to have more classes using it.

The perception of undergraduate students towards the traditional teaching methods in the morphologic sciences shows that they consider learning anatomy hard, demotivating, with a great deal of information to memorize, little comprehension, highly and quickly forgetful, with great difficulty of visualization and no retention of knowledge to the posterior clinical application (MILLER, PERROTTI, SILVERTHORN et al., 2002; PRITI and ZIMITAT, 2007; RAO and RAO, 2007; BERGMAN, PRINCE, DRUKKER et al., 2008; COSTA, GAMA and SILVA, 2010).

More recent pedagogical theories indicate that when the apprentices comprehend the involved objects in a classroom and notice in which context those objects should be studied they start getting involved in a more active manner (COLLINS, 2004). Finding pedagogical tools that can make students feel challenged and motivated to learn is fundamental and, accordingly to our results, radiology can print this characteristic in the apprenticeship of gross anatomy.

Table 2. Spearman correlation coefficient (r) to instrument's more stable questions according to Chronbach's alpha analysis.

\begin{tabular}{|c|c|c|c|c|c|c|c|c|c|c|c|c|c|c|}
\hline & & 2 & 7 & 8 & 11 & 12 & 16 & 3 & 19 & 20 & 24 & 25 & 26 & 27 \\
\hline \multirow{2}{*}{1} & $\mathrm{R}$ & 0.395 & 0.414 & 0.439 & 0.383 & 0.404 & 0.307 & 0.342 & 0.254 & 0.341 & 0.423 & 0.380 & 0.393 & 0.359 \\
\hline & $\mathrm{P}$ & $<0.001$ & $<0.001$ & $<0.001$ & $<0.001$ & $<0.001$ & 0.002 & 0.001 & 0.011 & 0.001 & $<0.001$ & $<0.001$ & $<0.001$ & $<0.001$ \\
\hline \multirow{2}{*}{2} & $\mathrm{R}$ & 1 & 0.357 & 0.408 & 0.365 & 0.520 & 0.346 & 0.342 & 0.247 & 0.286 & 0.353 & 0.417 & 0.303 & 0.342 \\
\hline & $\mathrm{P}$ & & $<0.001$ & $<0.001$ & $<0.001$ & $<0.001$ & $<0.001$ & 0.001 & 0.013 & 0.004 & $<0.001$ & $<0.001$ & 0.002 & 0.001 \\
\hline \multirow{2}{*}{7} & $\mathrm{R}$ & & 1 & 0.494 & 0.484 & 0.484 & 0.404 & 0.460 & 0.503 & 0.329 & 0.377 & 0.464 & 0.520 & 0.556 \\
\hline & $\mathrm{P}$ & & & $<0.001$ & $<0.001$ & $<0.001$ & $<0.001$ & $<0.001$ & $<0.001$ & 0.001 & $<0.001$ & $<0.001$ & $<0.001$ & $<0.001$ \\
\hline \multirow{2}{*}{8} & $\mathrm{R}$ & & & 1 & 0.162 & 0.316 & 0.438 & 0.343 & 0.484 & 0.353 & 0.346 & 0.377 & 0.448 & 0.398 \\
\hline & $\mathrm{P}$ & & & & 0.108 & 0.001 & $<0.001$ & $<0.001$ & $<0.001$ & $<0.001$ & $<0.001$ & $<0.001$ & $<0.001$ & $<0.001$ \\
\hline \multirow{2}{*}{11} & $\mathrm{R}$ & & & & 1 & 0.670 & 0.162 & 0.340 & 0.387 & 0.274 & 0.544 & 0.584 & 0.235 & 0.393 \\
\hline & $\mathrm{P}$ & & & & & $<0.001$ & 0.108 & 0.001 & $<0.001$ & 0.006 & $<0.001$ & $<0.001$ & 0.018 & $<0.001$ \\
\hline \multirow{2}{*}{12} & $\mathrm{R}$ & & & & & 1 & 0.316 & 0.380 & 0.408 & 0.413 & 0.598 & 0.644 & 0.448 & 0.421 \\
\hline & $\mathrm{P}$ & & & & & & 0.001 & $<0.001$ & $<0.001$ & $<0.001$ & $<0.001$ & $<0.001$ & $<0.001$ & $<0.001$ \\
\hline \multirow{2}{*}{16} & $\mathrm{R}$ & & & & & & 1 & 0.343 & 0.593 & 0.464 & 0.361 & 0.340 & 0.531 & 0.521 \\
\hline & $\mathrm{P}$ & & & & & & & $<0.001$ & $<0.001$ & $<0.001$ & $<0.001$ & 0.001 & $<0.001$ & $<0.001$ \\
\hline \multirow{2}{*}{17} & $\mathrm{R}$ & & & & & & & 1 & 0.281 & 0.250 & 0.365 & 0.355 & 0.467 & 0.410 \\
\hline & $\mathrm{P}$ & & & & & & & & 0.005 & 0.012 & $<0.001$ & $<0.001$ & $<0.001$ & $<0.001$ \\
\hline \multirow{2}{*}{19} & $\mathrm{R}$ & & & & & & & & 1 & 0.354 & 0.395 & 0.421 & 0.607 & 0.516 \\
\hline & $\mathrm{P}$ & & & & & & & & & $<0.001$ & $<0.001$ & $<0.001$ & $<0.001$ & $<0.001$ \\
\hline \multirow{2}{*}{20} & $\mathrm{R}$ & & & & & & & & & 1 & 0.346 & 0.365 & 0.455 & 0.475 \\
\hline & $\mathrm{P}$ & & & & & & & & & & $<0.001$ & $<0.001$ & $<0.001$ & $<0.001$ \\
\hline \multirow{2}{*}{24} & $\mathrm{R}$ & & & & & & & & & & 1 & 0.680 & 0.433 & 0.389 \\
\hline & $\mathrm{P}$ & & & & & & & & & & & $<0.001$ & $<0.001$ & $<0.001$ \\
\hline \multirow{2}{*}{25} & $\mathrm{R}$ & & & & & & & & & & & 1 & 0.403 & 0.384 \\
\hline & $\mathrm{P}$ & & & & & & & & & & & & $<0.001$ & $<0.001$ \\
\hline \multirow{2}{*}{26} & $\mathrm{R}$ & & & & & & & & & & & & 1 & 0.444 \\
\hline & $\mathrm{P}$ & & & & & & & & & & & & & $<0.001$ \\
\hline
\end{tabular}


Traditionally the use of cadaver in the human anatomy laboratories approaches with the students themes like respect towards another human being's body. Anatomy frequently is pointed out as promoter of humanist values, specifically when introducing delicate themes such as death.

However, there is a lack of evidences about such benefits and some believe that the early introduction to the topic of death can lead the first-year students to an unnecessary stressful situation, promoting inadequate attitudes and causing desensitization (MCLACHLAN, BLIGH, BRADLEY et al., 2004). The use of learning tools that can develop humanist values without desensitizing students becomes important.

Our study has shown that the greatest part of the participant students was not troubled to observe the anatomical structures in the diagnostic images and after the class still became more appreciative of the human body. There has been a positive correlation between the increase in the human body appreciation and the will to study more and comprehend better the human anatomy. Just as other authors (BOHL, FRANCOIS and GEST, 2011), this study shows that radiology can be a useful tool to lead medical undergraduate students to realize the complexity of the human body and make them even more aware and sensitive to the respect, compassion and necessary professionalism that should be devoted to it, especially for our school, where cadavers are not used.

In this study the greatest part of the participant reported that they were able to identify and point out anatomic structures requested by the professor in the diagnostic images. We suggest that the choice of structures should privilege initially the most commonly used diagnostic images of each corporal system and the study of normal structures in the expense of pathological ones. As students' progress in learning human morphology and semiology more complex diagnostic images with pathological structures can be introduced (MIRSADRAEE, MANKAD, MCCOUBRIE et al., 2012).

We think the study of anatomy in diagnostic images can also allow the vertical integration of the basic sciences in the medical curriculum favoring the memorization and retention of the acquired knowledge in the beginning of the medical training. Great part of the interviewed students realizes the importance that the human anatomy knowledge has for its professional career and almost all of them consider that the classes that use such types of tools are useful to establish a correlation between theory and clinic.

The perception of a greatest retention of anatomic knowledge also was cited as positive for the largest part of the students while studying radiology. Frequently the human anatomy courses is pointed out by our students as demanding of a great deal of memorization and the use of this tool allows the correlation between the human structure, the clinical concepts and also other basic sciences, facilitating the comprehension of what is being studied and consequently the retention of this knowledge.

The difficulty in retaining anatomic knowledge for posterior application in the clinical practice is a common complaint (BOHL, FRANCOIS and GEST, 2011; LAZARUS, CHINCHILLI, LEONG et al., 2012; PHILLIPS, SMITH, ROSS et al., 2012; SCARPA and CHANDRATILAKE, 2012; HATTAM, 2013). We believe that the use of multiple learning tools (anatomic resin models, radiology, dissection and others) allow its correlation with the clinical practice improving the knowledge retention. In this particular study the majority of students correlated the applied knowledge to the clinical practice and increase on the will to learn more and comprehend better the human body structure.

In general, the majority of the participant students consider that they were able to learn human anatomy in the diagnostic images. The perception of the three dimensionality and its spatial relations between organs and anatomic structures is a fundamental competency for the medical diagnosis. The possibility for training these aspects already in the first year of medical graduation makes that the students feel more secure, prepared and can be of great benefit to the future acquisition of diagnostic imaging skills.

In another study, also with first-year undergraduate medical students, it has been observed that they feel safer to execute invasive procedures after learning human anatomy with the help of ultrasound (BROWN, ADHIKARI, MARX et al., 2012). Other studies also demonstrate high acceptance of radiology between first-year undergraduate students in the learning of human anatomy (BOHL, FRANCOIS and GEST, 2011 ; LAZARUS, CHINCHILLI, LEONG et al., 2012; PHILLIPS, SMITH, ROSS et al., 2012; SCARPA and CHANDRATILAKE, 2012; HATTAM, 2013) and that it can contribute to learning surface anatomy (KOTZÉ, MOLE and GREYLING, 2012).

Even though a very small part of students will become radiology specialists (KHALIL, PAAS, JOHNSON et al., 2008), all should acquire minimal knowledge in the elementary image diagnostic and be able to dialogue with specialists. Diagnostic radiology performs an important role in contemporary medicine and the interpretation of the radiological images to predict clinical conditions requires basic anatomy knowledge (KHALIL, PAAS, JOHNSON et al., 2008).

Many medicine undergraduate students consider that their anatomy knowledge is insufficient and they feel insecure to act professionally (HATTAM, 2013). The integration of the anatomy and the radiology curriculums can change this perception since majority of students in this study reported feeling more able to speak to their future patients after radiology classes.

Besides, the training in the aspects related to diagnosis in basic sciences courses can help to reduce time and cost in the medical schools. The use of radiology in the human anatomy classes presented cost zero, making this an ideal tool to complement the anatomy knowledge of future doctors.

The elimination of the use of cadaver in some medical schools has led to the use of anatomic models in resin. Although this material has great validity to learning of human anatomy and presents great resemblance to real organs, the models do not allow the visualization of anatomic variations of size, form, distribution and positioning of in vivo structures. The use of radiology allows students to observe and comprehend such variations, a fundamental competency to the clinical exam and diagnosis, complementing the medical learning (STRKALJ, SPOCTER and WILKINSON, 2011).

\section{Conclusions}

The majority of first-year undergraduate medicine students evaluated as positive and beneficial the use of radiology to teach human anatomy. Students considered that this tool increases the interest for anatomy and that it can increase and facilitate learning and performance in the clinical practice. The results shows that according to students' opinion the usage of 
radiology can be an excellent complement in human anatomy learning and can induce us to think it can prepare and train more competent doctors in diagnostic imaging.

Nevertheless, other studies are necessary to demonstrate the long-term retention of what was learnt and if - for a fact students that went through the experience of using radiology will present a superior professional performance.

Acknowledgements: We thank Bruno Rodrigues, Cley Jardeweski and Creusa Maria Roveri Dal Bó for expert technical help.

\section{References}

AGGARWAL, R., BROUGH, H. and ELLIS, H. Medical student participation in surface anatomy classes. Clinical Anatomy, 2006, vol. 19, n. 7, p. 627-631. http://dx.doi.org/10.1002/ca.20225. PMid:16302232.

BERGMAN, EM., PRINCE, KJ., DRUKKER, J., VAN DER VLEUTEN, CP. and SCHERPBIER, AJ. How much anatomy is enough? Anatomical Sciences Education, 2008, vol. 1, n. 4, p. 184188. http://dx.doi.org/10.1002/ase.35. PMid:19177406.

BOHL, M., FRANCOIS, W. and GEST, T. Self-guided clinical cases for medical students based on postmortem CT scans of cadavers. Clinical Anatomy, 2011, vol. 24, n. 5, p. 655-663. http://dx.doi. org/10.1002/ca.21143. PMid:21387416.

BROWN, B., ADHIKARI, S., MARX, J., LANDER, L. and TODD, GL. Introduction of ultrasound into gross anatomy curriculum: perceptions of medical students. The Journal of Emergency Medicine, 2012, vol. 43, n. 6, p. 1098-1102. http://dx.doi.org/10.1016/j. jemermed.2012.01.041. PMid:22459597.

COLLETT, T., KIRVELL, D., NAKORN, A. and MCLACHLAN, JC. The role of living models in the teaching of surface anatomy: some experiences from a UK Medical School. Medical Teacher, 2009, vol. 31 , n. 3, p. e90-e96. http://dx.doi.org/10.1080/01421590802516731. PMid:19089727.

COLLINS, J. Education techniques for lifelong learning principles of adult learning. Radiographics, 2004, vol. 24, n. 5, p. 1483-1489. http://dx.doi.org/10.1148/rg.245045020. PMid:15371622.

COSTA, AP., GAMA, EF. and SILVA, SAPS. The formation of the physical education professional: teaching the discipline of human anatomy. Journal of Morphological, 2010, vol. 27, n. 2, p. 105-111.

FINN, GM. and MCLACHLAN, JC. A qualitative study of student responses to body painting. Anatomical Sciences Education, 2010, vol. 3, n. 1, p. 33-38. PMid:19918974.

GUNDERMAN, RB. and WILSON, PK. Viewpoint: exploring the human interior: the roles of cadaver dissection and radiologic imaging in teaching anatomy. Academic Medicine, 2005, vol. 80, n. 8, p. 745749. http://dx.doi.org/10.1097/00001888-200508000-00008. PMid:16043529.

HATTAM, AT. Incorporating clinically relevant radiology teaching into a medical student-initiated anatomy education programme. Journal of Medical Imaging and Radiation Oncology, 2013, vol. 57, n. 3, p. 348. http://dx.doi.org/10.1111/1754-9485.12061. PMid:23721145.

KHALIL, MK., PAAS, F., JOHNSON, TE., SU, YK. and PAYER, AF. Effects of instructional strategies using cross sections on the recognition of anatomical structures in correlated CT and MR images. Anatomical Sciences Education, 2008, vol. 1, n. 2, p. 75-83. http:// dx.doi.org/10.1002/ase.19. PMid:19177385.

KOTZÉ, SH., MOLE, CG. and GREYLING, LM. The translucent cadaver: an evaluation of the use of full body digital X-ray images and drawings in surface anatomy education. Anatomical Sciences Education,
2012, vol. 5, n. 5, p. 287-294. http://dx.doi.org/10.1002/ase.1277. PMid:22539465.

LAZARUS, MD., CHINCHILLI, VM., LEONG, SL. and KAUFFMAN JUNIOR, GL. Perceptions of anatomy: critical components in the clinical setting. Anatomical Sciences Education, 2012, vol. 5, n. 4, p. 187-199. http://dx.doi.org/10.1002/ase.1281. PMid:22532497.

LUFLER, RS., ZUMWALT, AC., ROMNEY, CA. and HOAGLAND, TM. Incorporating radiology into medical gross anatomy: does the use of cadaver CT scans improve students' academic performance in anatomy? Anatomical Sciences Education, 2010, vol. 3, n. 2, p. 56-63. PMid:20213692.

MARKER, DR., BANSAL, AK., JULURU, K. and MAGID, D. Developing a radiology-based teaching approach for gross anatomy in the digital era. Academic Radiology, 2010, vol. 17, n. 8, p. 1057-1065. http://dx.doi.org/10.1016/j.acra.2010.02.016. PMid:20447843.

MCLACHLAN, JC., BLIGH, J., BRADLEY, P. and SEARLE, J. Teaching anatomy without cadavers. Medical Education, 2004, vol. 38, n. 4, p. 418-424. http://dx.doi.org/10.1046/j.13652923.2004.01795.x. PMid:15025643.

MCMENAMIN, PG. Body painting as a tool in clinical anatomy teaching. Anatomical Sciences Education, 2008, vol. 1, n. 4, p. 139144. http://dx.doi.org/10.1002/ase.32. PMid:19177400.

MILES, KA. Diagnostic imaging in undergraduate medical education: an expanding role. Clinical Radiology, 2005, vol. 60, n. 7, p. 742-745. http://dx.doi.org/10.1016/j.crad.2005.02.011. PMid:15978883.

MILLER, SA., PERROTTI, W., SILVERTHORN, DU., DALLEY, AF. and RAREY, KE. From college to clinic: reasoning over memorization is key for understanding anatomy. The Anatomical Record, 2002, vol. 269, n. 2, p. 69-80. http://dx.doi.org/10.1002/ar.10071. PMid:12001213.

MIRSADRAEE, S., MANKAD, K., MCCOUBRIE, P., ROBERTS, T. and KESSEL, D. Radiology curriculum for undergraduate medical studies: a consensus survey. Clinical Radiology, 2012, vol. 67, n. 12, p. 1155-1161. http://dx.doi.org/10.1016/j.crad.2012.03.017. PMid:22705185.

PHILLIPS, AW., SMITH, SG., ROSS, CF. and STRAUS, CM. Improved understanding of human anatomy through self-guided radiological anatomy modules. Academic Radiology, 2012, vol. 19, n. 7, p. 902-907. http://dx.doi.org/10.1016/j.acra.2012.03.011. PMid:22537504.

PRITI, P. and ZIMITAT, C. Medical students' learning of anatomy: memorisation, understanding and visualisation. Medical Education, 2007, vol. 41, n. 1, p. 7-14. http://dx.doi.org/10.1111/j.13652929.2006.02643.x. PMid:17209887.

RAO, KH. and RAO, RH. Perspectives in medical education 5. Implementing a more integrated, interactive and interesting curriculum to improve Japanese medical education. The Keio Journal of Medicine, 2007, vol. 56, n. 3, p. 75-84. http://dx.doi.org/10.2302/kjm.56.75. PMid:17906418.

REES, CE., BRADLEY, P., COLLETT, T. and MCLACHLAN, JC. Over my dead body? The influence of demographics on students' willingness to participate in peer physical examination. Medical Teacher, 2005, vol. 27, n. 7, p. 599-605. http://dx.doi. org/10.1080/01421590500237671. PMid:16332551.

SCARPA, S. and CHANDRATILAKE, M. The weak relationship between anatomy competence and clinical skills in junior medical students. Anatomical Sciences Education, 2012, vol. 5, n. 4, p. 217 224. http://dx.doi.org/10.1002/ase.1272. PMid:22467202.

STRKALJ, G., SPOCTER, MA. and WILKINSON, AT. Anatomy, medical education, and human ancestral variation. Anatomical 
Sciences Education, 2011, vol. 4, n. 6, p. 362-365. http://dx.doi. org/10.1002/ase.258. PMid:22021152.

WRIGHT, SJ. Student perceptions of an upper-level, undergraduate human anatomy laboratory course without cadavers. Anatomical Sciences Education, 2012, vol. 5, n. 3, p. 146-157. http://dx.doi. org/10.1002/ase.1265. PMid:22362500.
ZUMWALT, AC., LUFLER, RS., MONTEIRO, J. and SHAFFER, K. Building the body: active learning laboratories that emphasize practical aspects of anatomy and integration with radiology. Anatomical Sciences Education, 2010, vol. 3, n. 3, p. 134-140. PMid:20496434.

Received October 14, 2014 Accepted July 12, 2016 